\title{
Application of the ribonuclease P (RNase P) RNA gene sequence for phylogenetic analysis of the genus Saccharomonospora
}

\author{
Myungsun Cho, Jung-Hoon Yoon, Sam-Bong Kim and Yong-Ha Park
}

\author{
Author for correspondence: Yong-Ha Park. Tel: +82428604620 . Fax: +82428604625. \\ e-mail: yhpark@kribb4680.kribb.re.kr
}

Korean Collection for Type Cultures (KCTC), Korea Research Institute of

Bioscience and Biotechnology (KRIBB), PO Box 115, Yusong, Taejon 305-600, Korea

\begin{abstract}
Sequences of the RNase P RNA gene were investigated for the phylogenetic analysis of the genus Saccharomonospora. Aligned nucleotide sequences, determined from the PCR-amplified RNase P RNA gene of representative strains of the genus Saccharomonospora, displayed $94 \cdot 2 \pm 1 \cdot 3 \%$ interspecific variances. The intraspecific similarity value was $99 \cdot 7-100 \%$ in all species tested. Saccharomonospora azurea K161' and 'Saccharomonospora caesia' K76 ${ }^{\top}$ displayed identical RNase P RNA gene sequences in the region that was determined and Saccharomonospora sp. K180 showed sequences distinct from validly described species with a similarity value of $94 \cdot 6 \pm 1.0 \%$. The phylogenetic trees constructed by aligning the sequences either within the genus Saccharomonospora or with other Gram-positive bacteria were similar to the ones derived using sequences of the 16S rDNA gene. Advantageous features of this gene for application as a molecular phyletic marker are discussed.
\end{abstract}

Keywords: Saccharomonospora, RNase P RNA gene sequence, phylogeny

\section{INTRODUCTION}

Bacterial taxonomy for the classification and nomenclature of micro-organisms has progressed rapidly over the last 20 years (Pace, 1997). Recently, determination of taxa has required the integration of different kinds of data for the purposes of delineation or classification. Thus, 'polyphasic data' combining phenotypic and genotypic data have now been widely applied for the classification of prokaryotic organisms or for the determination of the evolutionary distances between micro-organisms (Vandamme et al., 1996).

Of all the methods applied for bacterial phylogeny, the method based on sequence comparison of $16 \mathrm{~S}$ rDNA or rRNA has contributed most to modern taxonomy (Gutell et al., 1994; Woese, 1987). This has largely been made possible as a result of recent progress in molecular biology and database management techniques. Now, nearly full length sequences of $16 \mathrm{~S} \mathrm{rDNA}$ or rRNA from over 3600 different strains have been determined and are available through their own database (Maidak et al., 1997). This database supplies

\section{Abbreviation: ITS, internally transcribed spacer.}

The GenBank accession number for the RNase P RNA gene sequences reported in this paper are AF012792-AF012808 (see Table 1). other relevant information such as secondary structure and taxonomic significance in addition to the sequences. The comparison of $16 \mathrm{~S}$ rDNA or rRNA sequence is a generally accepted tool which gives the most reliable pattern for the classification of prokaryotic organisms. However, such data should not be used as the sole criteria for evaluating a particular species (Clayton et al., 1995). Usually two strains having rRNA similarity greater than $97 \%$ are very likely to be identical (Stackebrandt \& Goebel, 1994). However, the application of this rule for the classification of bacterial species sometimes does not give satisfactory results and many instances have been reported where two species, found to have distinct features by other standard methods, can still have over $97 \%$ nucleotide similarity in 16S rRNA sequences (Fox et al., 1992; Kim et al., 1995; Stackebrandt \& Goebel, 1994).

Lately, the sequences of the $16 \mathrm{~S}-23 \mathrm{~S}$ internally transcribed spacer (ITS) region in the rRNA operon has received attention as a suitable tool for the identification and typing of bacteria and has been frequently applied (Gürtler \& Stanisich, 1996; Leblond-Bourget et al., 1996; Yoon et al., 1997a). In many cases, it has been reported that the ITS region shows a higher variation rate than $16 \mathrm{~S}$ rRNA and can be applied as an 
alternative marker for the identification of species and closely related strains in cases where $16 \mathrm{~S}$ rDNA or rRNA sequences have a very high similarity value (over 97\%) (Yoon et al., 1997a). However, the presence of multiple rRNA alleles per single genome has often caused difficulties in sequence interpretation due to mixed sequence data. Researchers have sought alternative markers which may compensate for such problems, and the elongation factor Tu (Kamla et al., 1996), tRNA (Hofle, 1990), histone-like proteins (Valsangiacomo et al., 1997) and others (Vandamme et al., 1996) have been applied for this purpose.

In this study, we used the gene for the ribonuclease $\mathrm{P}$ (RNase P) RNA to evaluate whether this marker can provide rapid identification with reliable divergence between species and between strains belonging to the same species. RNase $\mathrm{P}$ is a ribonuclease which cleaves the $5^{\prime}$ leader sequences of tRNA precursors and is a ribonucleoprotein composed of RNA of about 400 nucleotides and a protein subunit of about 120 amino acids (Pace \& Brown, 1995). In a diverse range of bacteria, the RNA component of the RNase P is reported to be sufficient to catalyse the reaction at high ionic strength in vitro, and its biochemical characters as a ribozyme have been widely studied.

The genes encoding the RNA component of the RNase $P$ have been cloned from the archaea to man and now the sequences from about 200 organisms have been determined. Updated and compiled data containing sequences, sequence alignments, secondary structures and three dimensional models have become available through a database (Brown, 1997). Examination of the sequence variation between different organisms has revealed that the secondary structure, as well as its function, has been conserved throughout the evolutionary pathway. Comparative phylogenetic analysis based on secondary structures has demonstrated its evolutionary significance (Haas et al., 1994). Thus, the higher-order structure required to preserve its in vivo function seems to be maintained through the covariation of the sequences in helical regions. The phylogenetic tree based on the secondary structure of a diverse group of bacteria displays a core structure embedded in all types of bacterial RNase P RNA structures. However, each group still has its own distinct structure with respect to the number or length of the helical structures (Pace \& Brown, 1995). Sequence comparison has also revealed that there is a conserved core sequence, composed of approximately 225 nucleotides, which has a significant role as the minimum structure to maintain function over the course of evolution. Taken together with other studies, RNase $\mathrm{P}$ is believed to be an ancient molecule with a conserved function. It also contains characters suitable for its use as a phylogenetic marker, especially in prokaryotic taxa. However, its significance as a molecular phyletic marker has not been thoroughly tested in its application for interspecific or the intraspecific delineation of bacteria.
The genus Saccharomonospora was chosen to test the suitability of the RNase P RNA gene as a phylogenetic marker since the classification of this genus has been extensively studied in our laboratory and elsewhere. In particular, molecular phyletic aspects have been analysed using genomic DNA Southern blotting with rDNA probes (Yoon et al., 1996a) 16S rRNA gene sequence comparison (Warwick et al., 1994; Kim et al., 1995), RFLP analysis (Yoon et al., 1997b), multiplex PCR application (Yoon et al., 1996b) and sequence comparison of ITS in $16 \mathrm{~S}-23 \mathrm{~S}$ and $23 \mathrm{~S}-5 \mathrm{~S}$ regions (Yoon et al., 1997a). Saccharomonospora viridis, the type species of the genus Saccharomonospora, was isolated by Nonomura \& Ohara from soil in 1971 as a monosporic actinomycete containing mesodiaminopimelic acid, and possessing arabinose and galactose in the cell wall peptidoglycan (Nonomura \& Ohara, 1971). Features such as a non-fragmenting branched mycelium and aerial hyphae formation with single spores typify this genus. Other physical and chemical characters, including the composition of fatty acids and quinones, have also been determined. Saccharomonospora azurea (Runmao, 1987), Saccharomonospora cyanea (Runmao et al., 1988), Saccharomonospora glauca (Greiner-Mai et al., 1988) and 'Saccharomonospora caesia' (Greiner-Mai et al., 1987) are continuously isolated, although 'Saccharomonospora caesia', reported as the fifth taxon of this genus, has not been included in the Approved Lists of Bacterial Names (Skerman et al., 1980) or on subsequent Approved Lists or Validation Lists. Recent sequence analyses revealed that Saccharomonospora azurea and 'Saccharomonospora caesia' have identical sequences with respect to $16 \mathrm{~S}$ rDNA and ITSs, which strongly suggests that these two species should be unified as a single species (Kim et al., 1995; Yoon et al., 1997a). Since some kinds of saccharomonosporae are known to cause hypersensitivitiy pneumonitis and Saccharomonospora viridis has been implicated as a causal agent of farmer's lung disease (Greene et al., 1981), rapid identification methods for differentiation of these species are realized as being important.

In this study, we present the classification of the Saccharomonospora strains based on the sequence of the RNase P RNA gene and describe the significance and advantageous characters in the use of this gene as a phylogenetic marker.

\section{METHODS}

Organisms and culture condition. The growth conditions of the type strains and other related strains of the genus Saccharomonospora and the method for the isolation of chromosomal DNA are described elsewhere (Kim et al., 1995; Yoon et al., 1996a). The strains used in this study and their descriptions are shown in Table 1.

Amplification and cloning of RNase P RNA gene. PCR primers to amplify the gene for the RNase P RNA component were designed based on those of Brown et al. (1996) with some modifications. Modifications were introduced by considering the sequence of 'Streptomyces lividans' (GenBank accession no. M64552) and Streptomyces 
Table 1. Strains used in this study and GenBank accession numbers for RNase P RNA genes

\begin{tabular}{|c|c|c|c|}
\hline Lab. no. & Species & $\begin{array}{l}\text { Strain designation } \\
\text { and source* }\end{array}$ & $\begin{array}{l}\text { Accession } \\
\text { No. }\end{array}$ \\
\hline $\mathrm{K} 161^{\mathrm{T}}$ & Saccharomonospora azurea & H. Runmao, NA $128^{\mathrm{T}}$ & AF012792 \\
\hline $\mathrm{K} 76^{\mathrm{T}}$ & 'Saccharomonospora caesia' & KCTC $9152=$ INMI $19125^{\mathrm{T}}$ & AF012793 \\
\hline $\mathrm{K} 163$ & 'Saccharomonospora caesia' & DSM 43068 & AF012794 \\
\hline K182 & 'Saccharomonospora caesia' & E. Greiner-Mai, Kol 8 & AF012795 \\
\hline $\mathrm{K} 200$ & 'Saccharomonospora caesia' & J. Lacey, A1932 & AF012796 \\
\hline SB-01 & 'Saccharomonospora caesia' & S.-B. Kim & AF012797 \\
\hline SB-22 & 'Saccharomonospora caesia' & S.-B. Kim & AF012798 \\
\hline $\mathrm{K} 169^{\mathrm{T}}$ & Saccharomonospora glauca & DSM 43769 & AF012799 \\
\hline K202 & Saccharomonospora glauca & J. Ruan, 350 & AF012800 \\
\hline K194 & Saccharomonospora glauca & J. Lacey, A66 & AF012801 \\
\hline K195 & Saccharomonospora glauca & J. Lacey, A1450 & $\mathrm{AF} 012802$ \\
\hline K180 & Saccharomonospora sp. & A. J. McCarthy & $\mathrm{AF} 012803$ \\
\hline $\mathrm{K} 168^{\mathrm{T}}$ & Saccharomonospora cyanea & H. Runmao, NA-134 & $\mathrm{AF} 012804$ \\
\hline $\mathrm{K} 73^{\mathrm{T}}$ & Saccharomonospora viridis & NCIMB 9602 & AF012805 \\
\hline K197 & Saccharomonospora viridis & J. Lacey, A1905 & AF012806 \\
\hline K185 & Saccharomonospora viridis & E. Greiner-Mai, Llv & AF012807 \\
\hline K 191 & Saccharomonospora viridis & E. Greiner-Mai, R25 & AF012808 \\
\hline
\end{tabular}

* Abbreviations: KCTC, Korean Collection for Type Cultures; DSM, Deutsche Sammlung von Mikroorganismen, Braunschweig, Germany; NCIMB, National Collection of Industrial and Marine Bacteria, Aberdeen, UK.

bikiniensis (GenBank accession no. M64290), since the genera Sacharomonospora and Streptomyces are actinomycetes. The sequences of the primers RNP1 and RNP2 were 5' GGGGATCCGAGGAAMGTCCGGGCTC 3' (M $=\mathrm{A}$ or $\mathrm{G})$ and 5' CGGAATTCTAMGCCGGRTTCTGT $3^{\prime}(\mathrm{M}=\mathrm{A}$ or $\mathrm{C}, \mathrm{R}=\mathrm{A}$ or $\mathrm{G})$, respectively. Amplification conditions were the same as those described by Yoon et al. (1997a) and the PCR products were cloned into the $B a m \mathrm{HI}-E^{\prime} \circ \mathrm{RI}$ sites of either pGEM3zf or pGEM7zf (Promega). General techniques for DNA manipulation were as described by Sambrook et al. (1989).

Nucleotide sequence determination. Nucleotide sequences were determined using the T7 Sequencing kit of Pharmacia Biotech or the Sequenase version 2.0 kit from United States Biochemicals with the T7 (5'-TAATACGACTCACTATAGGGCGA-3') or SP6 primers (5'-ATTTAGGTGACACTATAGAATACT-3'). Two primers (RNP3, 5'-GTGTAAGAGACCACCAGCGC-3' and RNP4, 5'-CCTTGCTCCGGGTGGGGTTTACC-3') were additionally designed based on the results of sequencing and were further used for sequencing of the complementary strands.

Data analysis. The sequences of the RNase P RNA gene of the genus Saccharomonospora were aligned with those of other Gram-positive bacteria using CLUSTAL W software (Thompson et al., 1994) followed by manual corrections. GenBank accession numbers and retrieved nucleotide (nt) positions for aligning the sequences are as follows: 'Streptomyces lividans' (M64552, nt 1436-1780), Streptomyces bikiniensis (M64290, nt 136-477), Bacillus brevis (M19023, nt 53-394), Bacillus stearothermophilus (M19021, nt 44 400), Bacillus megaterium (M19022, nt 40-391), Bacillus subtilis (M13175, nt 43-384), Mycoplasma hyopneumoniae (X69982, nt 119-422), Mycoplasma pneumoniae (RNase P RNA database nt 31-326), Mycoplasma flocculare (X69983, nt 116-426), Mycoplasma capricolum (D13066, nt 98-397), Mycoplasma genitalium (RNase P RNA database nt 41-338), Heliobacterium mobilis (U64882, nt 1-342), Lactobacillus acidophilus (U64883, nt 1-328), Streptococcus faecalis (U64887, nt 1-331), Saccharomonospora faecium (U64886, nt 1-331). Trees were constructed using the neighbour-joining method (Saitou \& Nei, 1987) from a distance matrix calculated by the CLUSTAL w software. The topologies of the trees were evaluated by performing a bootstrap analysis (1000 replications) of the sequence data with CLUSTAL w software.

\section{RESULTS}

\section{Phylogenetic analysis using the RNase P RNA gene within the genus Saccharomonospora}

The genes encoding the RNase P RNA in the genus Saccharomonospora were amplified by PCR using primers designed based on the comparative analysis of sequences reported from other organisms. The sizes of the PCR products generated by the primers RNP1 and RNP2 were approximately $340 \mathrm{bp}$ in all cases in the genus Saccharomonospora. This size represented over $85 \%$ of the known size of RNase P RNA. The PCR products corresponded to the sequences of the same gene from Streptomyces bikiniensis or 'Streptomyces lividans' though lacking the first 40 bases (Brown, 1997; Morse \& Schmidt, 1992; Shareck et al., 1995). Thus this size was believed to contain the most sequence information of this gene and was deemed suitable for testing as a molecular phyletic marker. Nucleotide sequences were determined after the PCR products had been cloned into the cloning vector. Thus 
Table 2. Levels of nucleotide similarity with or without gaps included for the RNase P RNA genes in the representative strains of the genus Saccharomonospora and other Gram-positive bacteria

The values on the lower left are levels of nucleotide similarity, and the values on the upper right are those with gaps included.

\begin{tabular}{|c|c|c|c|c|c|c|c|c|c|c|c|c|c|}
\hline \multirow[t]{2}{*}{ Strains } & \multicolumn{13}{|c|}{ Percentage similarity to: } \\
\hline & 1 & 2 & 3 & 4 & 5 & 6 & 7 & 8 & 9 & 10 & 11 & 12 & 13 \\
\hline 1 Saccharomonospora azurea $\mathrm{K} 161^{\mathrm{T} *}$ & & $99 \cdot 7$ & $95 \cdot 6$ & $95 \cdot 3$ & $95 \cdot 6$ & $95 \cdot 9$ & $94 \cdot 4$ & $94 \cdot 1$ & $80 \cdot 3$ & $75 \cdot 3$ & $50 \cdot 9$ & $41 \cdot 6$ & $50 \cdot 7$ \\
\hline 2 'Saccharomonospora caesia' SB-22 & $99 \cdot 7$ & & $95 \cdot 3$ & $95 \cdot 0$ & $95 \cdot 3$ & $95 \cdot 6$ & $94 \cdot 1$ & $93 \cdot 8$ & $80 \cdot 6$ & $75 \cdot 3$ & $51 \cdot 2$ & $40 \cdot 9$ & $50 \cdot 5$ \\
\hline 3 Saccharomonospora glauca $\mathrm{K} 169^{\mathrm{T}} \uparrow$ & $95 \cdot 9$ & $95 \cdot 6$ & & $99 \cdot 7$ & $95 \cdot 3$ & $94 \cdot 7$ & $93 \cdot 3$ & $93 \cdot 3$ & $80 \cdot 4$ & $75 \cdot 1$ & $52 \cdot 1$ & $42 \cdot 5$ & $49 \cdot 9$ \\
\hline 4 Saccharomonospora glauca K194 & $95 \cdot 6$ & $95 \cdot 3$ & $99 \cdot 7$ & & $95 \cdot 3$ & $94 \cdot 4$ & $93 \cdot 0$ & $93 \cdot 0$ & $80 \cdot 7$ & $74 \cdot 9$ & $51 \cdot 9$ & $42 \cdot 2$ & $49 \cdot 9$ \\
\hline 5 Saccharomonospora sp. K180 & $96 \cdot 1$ & $95 \cdot 8$ & $96 \cdot 1$ & $96 \cdot 1$ & & $95 \cdot 3$ & $93 \cdot 5$ & $93 \cdot 3$ & $81 \cdot 7$ & $75 \cdot 0$ & $51 \cdot 6$ & $42 \cdot 8$ & $48 \cdot 8$ \\
\hline 6 Saccharomonospora cyanea $\mathrm{K} 168^{\mathrm{T}}$ & $95 \cdot 9$ & $95 \cdot 6$ & $95 \cdot 0$ & $94 \cdot 7$ & $95 \cdot 8$ & & $92 \cdot 4$ & $92 \cdot 1$ & $80 \cdot 2$ & $75 \cdot 9$ & $52 \cdot 7$ & $43 \cdot 3$ & $49 \cdot 3$ \\
\hline 7 Saccharomonospora viridis $\mathrm{K} 73^{\mathrm{T}}$ & $95 \cdot 0$ & $94 \cdot 7$ & $94 \cdot 1$ & $93 \cdot 8$ & $94 \cdot 7$ & $92 \cdot 9$ & & $99 \cdot 7$ & $78 \cdot 6$ & $75 \cdot 1$ & $51 \cdot 7$ & $42 \cdot 0$ & $51 \cdot 5$ \\
\hline 8 Saccharomonospora viridis $\mathrm{K} 185 \S$ & $94 \cdot 7$ & $94 \cdot 4$ & $94 \cdot 1$ & $93 \cdot 8$ & $94 \cdot 3$ & $92 \cdot 6$ & $99 \cdot 7$ & & $78 \cdot 6$ & $75 \cdot 4$ & $51 \cdot 5$ & $42 \cdot 2$ & $51 \cdot 5$ \\
\hline 9 Streptomyces bikiniensis & $82 \cdot 2$ & $83 \cdot 3$ & $83 \cdot 3$ & $83 \cdot 6$ & 84.4 & $83 \cdot 3$ & $80 \cdot 7$ & $80 \cdot 7$ & & $71 \cdot 3$ & $49 \cdot 3$ & $42 \cdot 1$ & $51 \cdot 2$ \\
\hline 10 Micrococcus luteus & $80 \cdot 9$ & $80 \cdot 9$ & $81 \cdot 5$ & $81 \cdot 2$ & $81 \cdot 1$ & $82 \cdot 1$ & $81 \cdot 3$ & $81 \cdot 6$ & $76 \cdot 4$ & & $48 \cdot 7$ & $42 \cdot 9$ & $51 \cdot 3$ \\
\hline 11 Bacillus subtilis & $61 \cdot 0$ & $61 \cdot 1$ & $65 \cdot 2$ & $64 \cdot 3$ & $60 \cdot 4$ & $61 \cdot 3$ & $62 \cdot 1$ & $61 \cdot 9$ & $57 \cdot 1$ & $56 \cdot 6$ & & $57 \cdot 0$ & $67 \cdot 3$ \\
\hline 12 Mycoplasma hyopneumoniae & $54 \cdot 3$ & $53 \cdot 4$ & $55 \cdot 8$ & $55 \cdot 0$ & $55 \cdot 2$ & $56 \cdot 1$ & $56 \cdot 2$ & $55 \cdot 8$ & $53 \cdot 1$ & $53 \cdot 8$ & $64 \cdot 1$ & & $42 \cdot 2$ \\
\hline 13 Lactobacillus acidophilus & $62 \cdot 1$ & $61 \cdot 5$ & $60 \cdot 2$ & $60 \cdot 8$ & $58 \cdot 6$ & $61 \cdot 8$ & $63 \cdot 3$ & $65 \cdot 1$ & $60 \cdot 4$ & $58 \cdot 3$ & $74 \cdot 3$ & $55 \cdot 4$ & \\
\hline
\end{tabular}

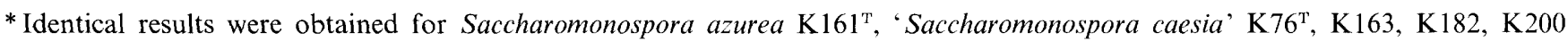
and SB-01.

$\dagger$ Identical results were obtained for Saccharomonospora glauca K169

¥Identical results were obtained for Saccharomonospora viridis $\mathrm{K} 73^{\mathrm{T}}$ and $\mathrm{K} 197$.

§Identical results were obtained for Saccharomonospora viridis K185 and K191.

the 17 bp sequence at the $5^{\prime}$ end and the 15 bp sequence at the $3^{\prime}$ end may differ from the original sequences.

The sequences determined from the six representative strains of the genus Saccharomonospora were aligned and those alignments were sufficient to show the interspecific variations. It was of interest that the gene also contained conserved and variable domains. The regions at nucleotides (nt) 94-105, nt 190-210 and nt 300-315 displayed sequence variation between representative strains of the genus Saccharomonospora. In particular, six bases around nt 94 showed strong divergence between species, indicating that sequence determination of this variable region may be sufficient for differentiating these species. In addition, sequences between nt 120-190 showed strong conservation between species. The sequences from Saccharomonospora azurea $\mathrm{K} 161^{\mathrm{T}}$ and 'Saccharomonospora caesia' $\mathrm{K} 76^{\mathrm{T}}$ were found to be identical agreeing with similar findings with respect to the data regarding 16S rDNA and ITS sequences in these strains. This result may verify the speculation that these two species are actually a single species (Kim et al., 1995; Yoon et al., 1997a). Also, Saccharomonospora sp. K180 exhibited sequences in the variable domains distinct from other validly described species while still showing strong similarity in the conserved domains. Together with the results from the 16S rDNA and ITS regions (Kim et al., 1995; Yoon et al., 1997a), this species should be assigned as a unique species within this genus.
Similarity between or within species of the genus Saccharomonospora was calculated with or without gaps included in the alignment (Table 2). The similarity values between the four validly described species were from $92.9 \%$ (Saccharomonospora viridis $\mathrm{K}^{7} 3^{\mathrm{T}}$ vs Saccharomonospora cyanea K168 ${ }^{\mathrm{T}}$ ) to $96.1 \%$ (Saccharomonospora azurea $\mathrm{K} 161^{\mathrm{T}}$, 'Saccharomonospora caesia' $\mathrm{K}^{7} 6^{\mathrm{T}}$ or Saccharomonospora glauca K $169^{\mathrm{T}}$ vs Saccharomonospora sp. K180) when gaps were excluded for calculation of the similarity (Table 2 ). When gaps were included, they were from $92.4 \%$ (Saccharomonospora viridis $\mathrm{K} 73^{\mathrm{T}}$ vs Saccharomono-

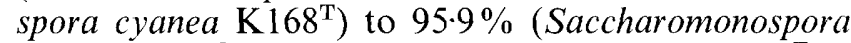
azurea $\mathrm{K} 161^{\mathrm{T}}$ or 'Saccharomonospora caesia' $\mathrm{K} 76^{\mathrm{T}}$ vs Saccharomonospora cyanea $\mathrm{K} 168^{\mathrm{T}}$ ) (Table 2). The strain Saccharomonospora viridis $\mathrm{K} 73^{\mathrm{T}}$ displayed the lowest level of similarity to other representative strains including Saccharomonospora sp. K180. Saccharomonospora $\mathrm{sp}$. K180 exhibited a mean similarity value of $95.4 \pm 0.7 \%$ with the four validly described species.

Intraspecific divergence was examined using six strains of 'Saccharomonospora caesia', four strains of Saccharomonospora glauca and four strains of Saccharomonospora viridis listed in Table 1. 'Saccharomonospora caesia' strain SB-22 showed one nucleotide alteration at $\mathrm{nt} 195$ while the other four 'Saccharomonospora caesia' strains displayed identical sequences to that of 'Saccharomonospora caesia' $\mathrm{K} 76^{\mathrm{T}}$. The nucleotide $\mathrm{A}$ at this position was replaced 


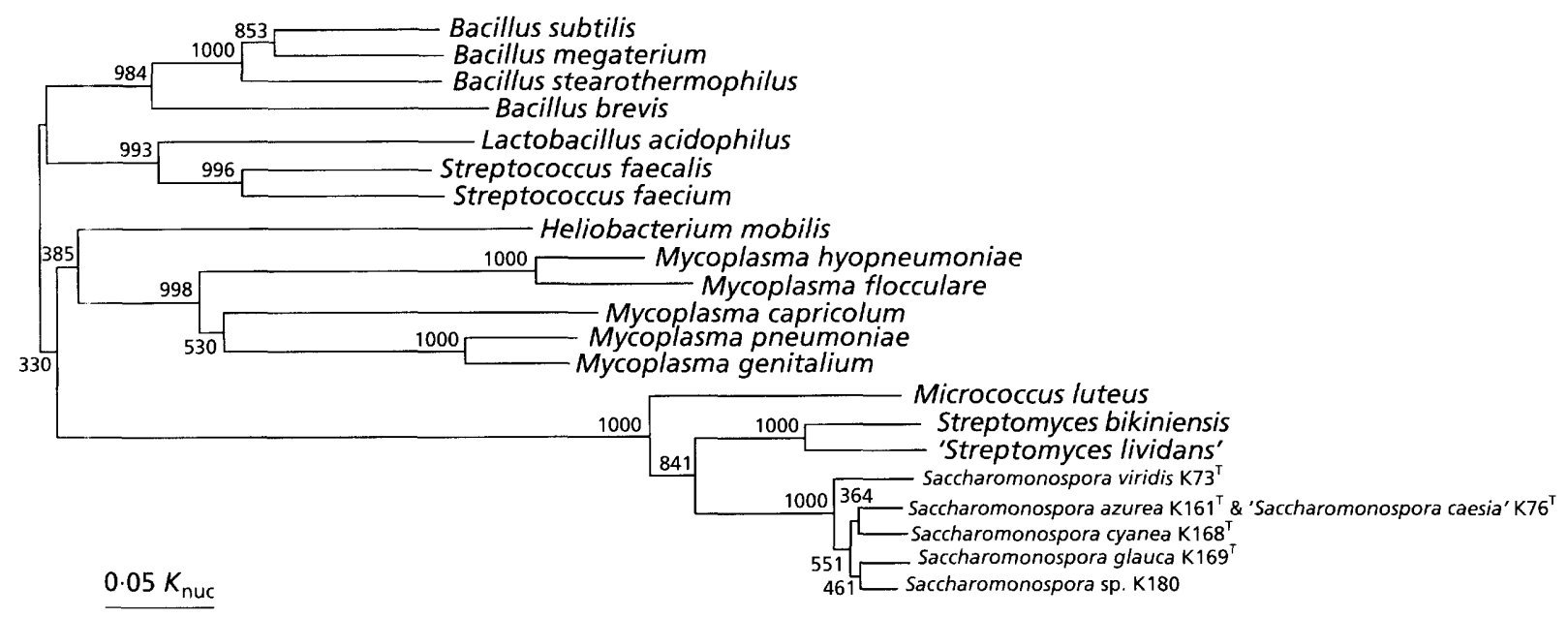

Fig. 1. Phylogenetic tree showing the genetic relationships of the genus Saccharomonospora with other Gram-positive bacteria. The GenBank accession numbers and sequence position applied for alignments are listed in Methods. The scale bar indicates 5 nucleotide substitutions per 100 nucleotides. Bootstrap confidence values by 1000 trials are shown at branching points.

with $G$ in strain SB-22. In the case of Saccharomonospora glauca, the nucleotide $\mathrm{T}$ at $\mathrm{nt} 244$ was substituted with C in strain K194, while the other two strains, K202 and K195, showed no sequence differences to Saccharomonospora glauca $\mathrm{K} 169^{\mathrm{T}}$. In the case of Saccharomonospora viridis, strains K185 and $\mathrm{K} 191$ had base A at nt 199 . This result represented $99 \cdot 7-100 \%$ intraspecific sequence similarities. Taken together, the data derived from sequence analysis strongly suggest that the sequence of the RNase P RNA gene in this single genus showed divergence between species with a range of variation sufficient to detect interspecific differences, while containing 99.7$100 \%$ intraspecific sequence similarities (Table 2).

The phylogenetic tree generated with these sequence data is shown in Fig. 1. Each species formed a distinct genetic lineage and showed clear inter- or intra-specific relationships. As in the case of $16 \mathrm{~S}$ rDNA sequences, Saccharomonospora viridis strains appeared to be the most distantly related species and Saccharomonospora sp. K180 showed a clearer branching point in this tree than was the case with respect to $16 \mathrm{~S}$ rDNA sequences (Kim et al., 1995). This strain also formed a separate lineage in the tree generated by ITS sequences (Yoon et al., 1997a).

\section{Phylogenetic analysis using the RNase P RNA gene with other Gram-positive bacteria}

In an attempt to determine whether the genus Saccharomonospora can form a distinct genetic cluster among prokaryotic taxa using the sequence of the RNase P RNA gene, the phylogenetic relationship was examined by aligning the sequences of members of this genus with those from other Gram-positive bacterial taxa. Thus far, the sequences of this gene have only been reported for five genera of high $\mathrm{G}+\mathrm{C}$ containing bacteria and about twenty genera of low $G+C$ containing bacteria (Brown, 1997). The sequences corresponding to the same region as determined in the genus Saccharomonospora in this study were retrieved from the GenBank database and appropriately aligned. The nucleotide positions and their GenBank accession numbers are listed in Methods. The level of nucleotide similarity between the sequences of these representative reference strains and those of the Saccharomonospora strains are also summarized in Table 2. Aligning these sequences required the introduction of several gaps due to the high divergence in the sequences between variable bacterial taxa. Thus, nucleotide similarity rates were calculated with or without gaps included. As expected, the highest nucleotide similarities were observed when compared to those of Streptomyces bikiniensis or 'Streptomyces lividans', which belong to the same order, Actinomycetales. The mean nucleotide similarity value between Streptomyces bikiniensis and representative strains of the Saccharomonospora genus was $82.6 \pm 1.9 \%$ and $80.15 \pm 1.5 \%$ with the gaps excluded or included, respectively. With other high- $\mathrm{G}+\mathrm{C}$ bacteria, Micrococcus luteus, gave a value of approximately $81.5 \pm 0.6 \%$ and $75.5 \pm 0.5 \%$ similarity to those genes in the genus Saccharomonospora with gaps excluded or included, respectively. However, the bacteria belonging to the low- $\mathrm{G}+\mathrm{C}$ subdivisions exhibited quite a low level of similarity (Table 2). The mean nucleotide similarity values with (or without) gaps between Bacillus subtilis, Mycoplasma hyopneumoniae and Lactobacillus acidophilus and the representative strains in the genus Saccharomonospora were $51.8 \pm$ $0.9 \% \quad(62.8 \pm 2.4 \%), 43 \pm 0.9 \% \quad(55.3 \pm 1.0 \%)$ and $50 \cdot 15 \pm 1 \cdot 4 \%(61 \cdot 0 \pm 2 \cdot 4 \%)$, respectively.

The phylogenetic tree was generated with the sequences of RNase P RNA from six representative strains of the genus Saccharomonospora, three high- 
$\mathrm{G}+\mathrm{C}$-and 13 low-G $+\mathrm{C}$-content bacterial species (Fig. 1). The genus Saccharomonospora formed a single genetic lineage among the Gram-positive bacterial taxa tested. The branching pattern displayed by the tree in Fig. 1 is quite similar to that derived from $16 \mathrm{~S}$ rDNA sequences (Maidak et al., 1997) or RNase $\mathrm{P}$ Database (Brown, 1997). Altogether, the RNase P RNA gene performed well as a functional marker for discriminating individual species and for determining the taxonomic relationship within the genus Saccharomonospora and provides the possibility of its application to other taxa.

\section{DISCUSSION}

In this study, we evaluated the RNase P RNA gene as a marker for the discrimination or classification of prokaryotic taxa, using the genus Saccharomonospora, and have demonstrated its usefulness. Since we have performed molecular phylogenetic studies on the genus Saccharomonospora using the 16S rDNA and ITS sequences (Kim et al., 1995; Yoon et al., 1997a), the evaluation or comparison of data obtained with different markers was possible.

In the sequence alignments, six representative strains of the genus Saccharomonospora exhibited sequence variation at distinct variable domains. Using the RNase P RNA gene, the mean nucleotide similarity was $94.5 \pm 1.6 \%$ among the representative strains of the genus Saccharomonospora. This value was intermediate between those obtained using sequences of the 16S rDNA $(97.6 \pm 1.3 \%$ ) (Kim et al., 1995) and ITS regions $(87 \cdot 6 \pm 4 \cdot 0 \%$ ) (Yoon et al., 1997a), with this genus (Table 2). As described above, the sequences at nt 90 showed strong variation in all the validly described Saccharomonospora species in this genus. The intraspecific variations in all tested strains were $99 \cdot 7-100 \%$. These results strongly suggest that sequence variation in the $\mathrm{RNase} P$ gene shows significant variation between species with negligible variation within species. The phylogenetic tree generated with the sequences, although only limited numbers of sequences were available, clearly demonstrates that the genus Saccharomonospora forms a single branching point with a reasonable degree of relatedness to other taxa (Fig. 1). Also, this study provides further evidence supporting previous speculations (Kim et al., 1995; Yoon et al., 1997a). These are (i) that Saccharomonospora azurea and 'Saccharomonospora caesia' may be an identical species and (ii) that Saccharomonospora $\mathrm{K} 180$ is a distinct species within this genus. Saccharomonospora azurea $\mathrm{K} 161^{\mathrm{T}}$ and 'Saccharomonospora caesia' $\mathrm{K} 76^{\mathrm{T}}$ had identical RNase P RNA sequences at the determined region and Saccharomonospora sp. K180 showed a sequence distinct from other validly described species with a $94.6 \pm 1.0 \%$ similarity value. DNA-DNA hybridization experiments, as a final validating criterion, are under progress to confirm our findings.

$\mathrm{RNase} \mathrm{P}$ is regarded as an interesting molecule since it is a holoenzyme consisting of protein and RNA components (Pace \& Brown, 1995). In addition to its unique biochemical character as a ribozyme in vitro, the conserved structure and universal function of the RNA component during the evolutionary pathway has made it an important molecule for researchers investigating molecular evolution (Haas et al., 1994; Pace \& Brown, 1995). In addition to its evolutionary significance, this molecule provides other attractive features for use as a phylogenetic marker. First, the size of the gene is less than $400 \mathrm{bp}$. In Escherichia coli, whose RNase P RNA has been most thoroughly characterized, it is known to be 377 bp (Lawrence et al., 1987). Although the full size of this gene in most prokaryotes is known to be about $400 \mathrm{bp}$, a $340 \mathrm{bp}$ portion that was amplified in this study turned out to be sufficient to display the sequence variations. Thus, sequence determination can be accomplished in less time and allow rapid identification or classification results. Although the sequences in this study were determined after the gene had been cloned into a vector, direct sequencing with internal primers would also be possible. This is thought to be highly advantageous since sequence determination of the $1500 \mathrm{bp}$ of $16 \mathrm{~S}$ rDNA requires considerably more time, labour and expense. Although partial sequences of the variable region in the $16 \mathrm{~S}$ rDNA have been used in some cases, it should be noted that these sequences should not be used as conclusive data for determination of species identity. Second, there is only a single locus coding this gene in a genome. In contrast to the multiple presence of rRNA operons in most bacterial genome, it is known that a single $r n p B$ gene encodes the RNase P RNA. While the multiple presence of the rRNA operons in a single genome generates diversity in length and sequence between species, such multiple numbers often cause serious problems for strain identification purposes, particularly in the analysis of ITS regions (Hain et al., 1997). When ITS regions are amplified by primers designed using conserved regions of rDNA sequences, either multiple numbers of products or a single-sized product composed of mixed bands can be generated causing difficulty in alignment and comparison of such sequences for classification. Such problems have been alleviated by high resolution electophoresis and GENESCAN 672 software (Hain et al., 1997). Thus, the homogeneity of the amplified product for the RNase P RNA gene was recognized as advantageous for simple interpretation of the data obtained.

Although we have tested the application of the RNase $P$ gene with only one genus in this study, we believe that the same approach can be extended to other genera and we are currently performing such experiments with other taxa, especially with actinomycetes whose RNase P RNA gene sequences have not been determined. In particular, it would be worthwhile investigating those species or strains having higher $16 \mathrm{~S}$ rDNA or rRNA similarities with complex pattern of ITS sequences. As discussed above, the variation rate 
RNase P RNA gene sequence of Saccharomonospora

in the RNase P RNA sequence was higher than that of $16 \mathrm{~S}$ rDNA or rRNA sequences in spite of its smaller size. In the genus Streptomyces, the RNase P sequences of Streptonyces bikiniensis and 'Streptomyces lividans' showed $88.4 \%$ sequence identity, while these two species had $96.8 \%$ sequence identity with respect to $16 \mathrm{~S}$ rDNA. Thus it is believed that extending the database of this gene would be very helpful for the discrimination of bacterial taxa as well as for our understanding of evolutionary pathways.

It is not expected that a single macromolecule can provide all information about rate, tempo, mode and distance of evolution. Depending on the marker applied, the knowledge we can obtain will be different. The more information that is obtained, the more our understanding of molecular evolution will be enhanced and we believe that the use of the RNase P RNA gene will contribute further to this end.

\section{ACKNOWLEDGEMENTS}

This work w as supported by grant HS1331 from the Ministry of Science and Technology of the Republic of Korea. Authors thank Martin Hector for programming 'PairPro', a calculation program for the similarity values, and Russell Davidson for reviewing the manuscript.

\section{REFERENCES}

Brown, J. W. (1997). The ribonuclease P database. Nucleic Acids Res 25, 263-264.

Brown, J. W., Nolan, J. M., Haas, E. S., Rubio, M. A. T., Major, F. \& Pace, N. R. (1996). Comparative analysis of ribonuclease P RNA using gene sequences from natural microbial populations reveals tertiary structural elements. Proc Natl Acad Sci USA 93, 3001-3006.

Clayton, R. A., Sutton, G., Hinkle, P. S., Bult, C., Jr \& Fields, C. (1995). Intraspecific variation in small-subunit $r$ RNA sequences in Genbank: why single sequences may not adequately represent prokaryotic taxa. Int J Syst Bacteriol 45, 595-599.

Fox, G. E., Wisotzkey, J. D. \& Jurtshuk, P., Jr (1992). How close is close: $16 \mathrm{~S}$ rRNA sequence identity may not be sufficient to guarantee species identity. Int J Syst Bacteriol 42, 166-170.

Greene, J. G., Treuhaft, M. W. \& Arnsell, R. M. (1981). Hypersensitivity pneumonitis due to Saccharomonospora viridis diagnosed by inhalation challenge. Ann Allergy 47, 449-452.

Greiner-Mai, E., Kroppenstedt, R. M., Korn-Wendisch, F. \& Kutzner, H. J. (1987). Morphological and biochemical characterization and emended descriptions of thermophilic actinomycetes species. Syst Appl Microbiol 9, 97-109.

Greiner-Mai, E., Korn-Wendisch, F. \& Kutzner, H. J. (1988). Taxonomic revision of the genus Saccharomonospora and description of Saccharomonospora glauca sp. nov. Int J Syst Bacteriol 38, 398-405.

Gürtler, V. \& Stanisich, V. A. (1996). New approaches to typing and identification of bacteria using the $16 \mathrm{~S}-23 \mathrm{~S}$ rDNA spacer region. Microbiology 142, 3-16.

Gutell, R. R., Larsen, N. \& Woese, C. R. (1994). Lessons from an evolving rRNA: $16 \mathrm{~S}$ and $23 \mathrm{~S}$ rRNA structures from a comparative perspective. Microbiol Rev 58, 10-26.
Haas, E. S., Brown, J. W., Pitulle, C. \& Pace, N. R. (1994). Further perspective on the catalytic core and secondary structure of ribonuclease P RNA. Proc Natl Acad Sci USA 91, 2527-2531.

Hain, T., Ward-Rainey, N., Kroppenstedt, R. M., Stackebrandt, E. \& Rainey, F. A. (1997). Discrimination of Streptomyces albidoflavus strains based on the size and number of $16 \mathrm{~S}-23 \mathrm{~S}$ ribosomal DNA intergenic spacers. Int $J$ Syst Bacteriol 47, 202-206.

Hofle, M. (1990). Transfer RNAs as genotypic fingerprints of eubacteria. Arch Microbiol 153, 299-304.

Kamla, V., Henrich, B. \& Hadding, U. (1996). Phylogeny based on elongation factor $\mathrm{Tu}$ reflects the phenotypic features of mycoplasma better than that based on 16S rRNA. Gene 171, 83-87.

Kim, S.-B., Yoon, J.-H., Kim, H., Lee, S. T., Park, Y.-H. \& Goodfellow, M. (1995). A phylogenetic analysis of the genus Saccharomonospora conducted with 16S rRNA gene sequences. Int J Syst Bacteriol 45, 351-356.

Lawrence, N. P., Richman, A., Amini, R. \& Altman, S. W. (1987). Heterologous enzyme function in Escherichia coli and the selection of genes encoding the catalytic RNA subunit of RNase P. Proc Natl Acad Sci USA 84, 6825-6829.

Leblond-Bourget, N., Philippe, H., Mangin, I. \& Decaris, B. (1996). $16 \mathrm{~S}$ rRNA and $16 \mathrm{~S}$ to $23 \mathrm{~S}$ internal transcribed spacer sequence analyses reveal inter- and intraspecific Bifidobacterium phylogeny. Int J Syst Bacteriol 46, 102-111.

Maidak, B. L., Olsen, G. J., Larsen, N., Overbeek, R., McCaughey, M. J. \& Woese, C. R. (1997). The RDP (Ribosomal database project). Nucleic Acids Res 25, 109-110.

Morse, D. P. \& Schmidt, F. J. (1992). Sequences encoding the protein and RNA components of ribonuclease P from Streptomyces bikiniensis var. zorbonensis. Gene 117, 61-66.

Nonomura, H. \& Ohara, Y. (1971). Distribution of actinomycetes in soil. X. New genus and species of monosporic actinomycetes. $J$ Ferment Technol 49, 895-903.

Pace, N. R. (1997). A molecular view of microbial diversity and the biosphere. Science 276, 734-740.

Pace, N. R. \& Brown, J. W. (1995). Evolutionary perspective on the structure and function of ribonuclease $\mathrm{P}$, a ribozyme. $J$ Bacteriol 177, 1919-1928.

Runmao, H. (1987). Saccharomonospora azurea sp. nov., a new species from soil. Int $J$ Syst Bacteriol 37, 60-61.

Runmao, H., Lin, C. \& Guizhen, W. (1988). Saccharomonospora cyanea sp. nov. Int J Syst Bacteriol 38, 444-446.

Saitou, N. \& Nei, M. (1987). The neighbor-joining method : a new method for reconstructing phylogenetic trees. Mol Biol Evol 4, 406-425.

Sambrook, J., Fritsch, E. F. \& Maniatis, T. (1989). Molecular Cloning: a Laboratory Manual, 2nd edn. Cold Spring Harbor, NY : Cold Spring Harbor Laboratory.

Shareck, F., Biely, P., Morosoli, R. \& Kluepfel, D. (1995). Analysis of DNA flanking the $x \ln B$ locus of Streptomyces lividans reveals genes encoding acetyl xylan esterase and the RNA component of ribonuclease P. Gene 153, 105-109.

Skerman, V. B. D., McGowan, V. \& Sneath, P. H. A. (editors) (1980). Approved lists of bacterial names. Int J Syst Bacteriol 30, 225-420.

Stackebrandt, E. \& Goebel, B. M. (1994). Taxonomic note: a place for DNA-DNA reassociation and 16S rRNA sequence analysis in the present species definition in bacteriology. Int $J$ Syst Bacteriol 44, 846-849.

Thompson, J. D., Higgins, D. G. \& Gibson, T. J. (1994). CLUSTAL 
$\mathrm{w}$ : improving the sensitivity of progressive multiple sequence alignment through sequence weighting, position specific gap penalties and weight matrix choice. Nucleic Acids Res 22. 4673-4680.

Valsangiacomo, C., Balmelli, T. \& Piffaretti, J.-C. (1997). A phylogenetic analysis of Borrelia burgdorferi sensu lato based on sequence information from the $h b b$ gene, coding for a histone-like protein. Int J Syst Bacteriol 47, 1-10.

Vandamme, P., Pot, B., Gillis, M., De Vos, P., Kersters, K. \& Swings, J. (1996). Polyphasic taxonomy, a consensus approach to bacterial systematics. Microbiol Rev 60, 407-438.

Warwick, S., Bowen, T., McVeigh, H. \& Embley, T. M. (1994). A phylogenetic analysis of the family Pseudonocardiacea and the genera Actinokineospora and Saccharothrix with 16S rRNA sequences and a proposal to combine genera Amycolata and Pseudonocardia in an emended genus Pseudonocardia. Int J Syst Bacteriol 44, 292-299.

Woese, C. R. (1987). Bacterial evolution. Microbiol Rev 51, 221-271.
Yoon, J.-H., Kim, H., Kim, S.-B., Kim, H.-J., Kim, W. Y., Lee, S. T. Goodfellow, M. \& Park, Y.-H. (1996a). Identification of Saccharomonospora strains with genomic DNA fragments and rRNA gene probes. Int J Syst Bacteriol 46, 502-505.

Yoon, J.-H., Lee, S. T., Shin, Y. K., Kim, S.-B., Kim, H.-J., Goodfellow, M. \& Park, Y.-H. (1996b). Rapid identification of Saccharomonospora strains by multiplex PCR using speciesspecific primers within the 16S rRNA gene. J Microbiol Methods 27, 89-95.

Yoon, J.-H., Lee, S. T., Kim, S.-B., Goodfellow, M. \& Park, Y.-H. (1997a). Inter- and intraspecific genetic analysis of the genus Saccharomonospora with $16 \mathrm{~S}$ to $23 \mathrm{~S}$ ribosomal DNA (rDNA) and $23 \mathrm{~S}$ to $5 \mathrm{~S}$ rDNA internally transcribed spacer sequences. Int J Syst Bacteriol 47, 661-669.

Yoon, J.-H., Lee, S. T., Kim, S.-B., Kim, W. Y., Goodfellow, M. \& Park, Y.-H. (1997b). Restriction fragment length polymorphism analysis of PCR-amplified $16 \mathrm{~S}$ ribosomal DNA for rapid identification of Saccharomonospora strains. Int J Syst Bacteriol 47, 111-114. 